\title{
Electrochemical Determination of Indole-3-carboxylic Acid Using Carboxyl Functionalized Multi-Walled Carbon Nanotubes Modified Glassy Carbon Electrode
}

\author{
X.L. Jia ${ }^{1}$, J.H. Ye ${ }^{1}$, F.Q.Wang ${ }^{1}$, Y.L. Hu ${ }^{1}$, M.Z. Zheng ${ }^{1}$, C.Z. Wu ${ }^{1,2, *}$ \\ ${ }^{1}$ Fujian Provincial Key Laboratory of Eco-Industrial Green Technology, Wuyi University, Wuyishan \\ 354300China. \\ ${ }^{2}$ College of Life Science, Fujian Agriculture and Forestry University, Fuzhou, 350002, China. \\ *E-mail: fjwcz@126.com
}

doi: $10.20964 / 2018.09 .49$

Received: 4 May 2018 / Accepted: 4 July 2018 / Published: 5 August 2018

\begin{abstract}
Indole-3-carboxylic acid (ICA) was detected by differential pulse voltammetry using a glassy carbon electrode (GCE) modified carboxylic multi-walled carbon nanotubes (MWCNTs-COOH). Electrochemical impedance spectroscopy (EIS) and different pulse voltammetry (DPV) were used to study electrochemical properties of the modified electrode. The modified electrode shows higher electrocatalytic activity toward the oxidation of Indole-3-carboxylic acid than those of the carbon electrode modified multi-walled carbon nanotubes or bare glassy carbon electrode. After the experimental conditions were optimized, the linear calibration curve was obtained in the range from 0.75 to $100 \mu \mathrm{mol} \cdot \mathrm{L}^{-1}$ with a low detection limit of $0.25 \mu \mathrm{mol} \cdot \mathrm{L}^{-1}(\mathrm{~S} / \mathrm{N}=3)$. The modified electrode was successfully used for the determination of the analytes in real samples, which obtained satisfactory results.
\end{abstract}

Keywords: Indole-3-carboxylic acid; carboxylic multi-walled carbon nanotubes; modified electrode; Electrochemical sensor

\section{FULL TEXT}

(C) 2018 The Authors. Published by ESG (www.electrochemsci.org). This article is an open access article distributed under the terms and conditions of the Creative Commons Attribution license (http://creativecommons.org/licenses/by/4.0/). 